\title{
Social measures for reducing exposure to secondhand smoke in migrant workers of sugarcane harvest in the lower northern region of Thailand
}

\author{
Narongsak Noosorn', Anukool Manoton², Rishad Choudhury Robin ${ }^{1,3}$
}

\begin{abstract}
INTRODUCTION The sugarcane harvest migrant workers are an underprivileged group in Thailand and have a high risk of exposure to secondhand smoke but are potentially neglected in health promotion interventions.

METHODS This three-phase study applied a mixed-method research approach. The data were collected from February to December 2019 from the Sukhothai province of Thailand. In Phase 1, the level of secondhand smoke exposure of the sugarcane harvest migrant workers at the worker camp was explored. The data were collected from 462 workers by questionnaires and from 24 sample participants in the group discussions about the factors leading to the exposure to secondhand smoke. Phase 2 was the provision and implementation of social measures for the health protection of migrant workers and families from exposure to secondhand smoke. In Phase 3, an evaluation of the health protection model for the migrant workers and families from secondhand smoke exposure was explored. RESULTS Workers aged $\leq 40$ years had 1.9 times higher exposure to secondhand smoke than workers aged $\geq 41$ years $(\mathrm{OR}=1.93 ; 95 \%$ CI: $1.24-3.01)$. Those who worked overtime had 1.7 times higher exposure to secondhand smoke than those who did not work overtime (OR=1.71; 95\% CI: 1.10-2.66). Social measures to prevent secondhand smoke were: given a warning, no rewards for cigarettes, designated smoking area, not asking the children to buy cigarettes, stop displaying cigarettes at grocery shops, and empowering woman to go against the smoking husband in the camp and the sugarcane field when the women, children, and nonsmokers are present. After implementing the measures, there was no exposure to secondhand smoke inside the room, cooking area, and at the quad in the camp center.
\end{abstract}

CONCLUSIONS Appropriate social measures for health protection can help to reduce exposure to secondhand smoke.

\section{AFFILIATION \\ 1 Faculty of Public Health, Naresuan University, Phitsanulok, Thailand 2 School of Medicine, University of Phayao, Phayao, Thailand \\ 3 Ministry of Health and Family Welfare Coordination Centre, Cox's Bazar, Bangladesh}

CORRESPONDENCE TO Narongsak Noosorn. Faculty of Public Health, Naresuan University, Phitsanulok 65000, Thailand. E-mail: nnoosorn@ yahoo.com ORCID ID: https://orcid. org/0000-0002-2814-6277

\section{KEYWORDS}

Thailand, secondhand smoke, social measures, migrant worker, health protection

Received: 16 January 2021 Revised: 1 June 2021

Accepted: 11 July 2021

\section{INTRODUCTION}

Tobacco smoking is one of the top public health issues, and about 1.1 billion people smoke different forms of tobacco around the world ${ }^{1,2}$. Around 7 million people die from a diverse use of tobacco, and for low- and middle-income countries, it is a tremendous burden because approximately $80 \%$ of the world's smokers live in this part of the world ${ }^{2}$. Besides, male smoker prevalence is high in the Western Pacific region, and for female smokers, Europe has the highest prevalence $^{3}$.

Globally, secondhand smoke (SHS) exposure is also an enormous burden as SHS is also responsible for 1.2 million deaths $\mathrm{s}^{4}$. SHS exposure has no safe limit $^{2}$. In developed countries, smoking causes $90 \%$ of lung cancers in men and up to $86 \%$ in women ${ }^{4,5}$. 
In the case of SHS exposure, the health effects are also huge as there are more than 7000 chemicals found in tobacco smoke, and many are responsible for cancer. Consequently, in adults, it causes different cardiovascular diseases such as heart attack, stroke, and other kinds of cancer ${ }^{6}$.

According to the Global Adult Tobacco Survey (GATS) by World Health Organization (WHO), the prevalence of tobacco smoking in Thailand is $23.7 \%$, whereas, among males, it is $45.6 \%$ and $3.1 \%$ among females. The GATS data show that the overall SHS exposure prevalence inside the home is $39.1 \%$ and $27.2 \%$ in the workplace ${ }^{7}$. Smoking is common among laborers ${ }^{8}$. However, controlling smoking in the workplace pointedly reduces SHS exposure ${ }^{9}$. Moreover, incentives may be cost-effective in increasing quitting smoking in the workplace setting ${ }^{10}$.

Sukhothai is one of the major provinces of sugar cane planting in Thailand, and several sugar factories employ hundreds of seasonal informal sugarcane harvest workers each year ${ }^{11}$. According to the legal provision regarding informal labor and the NonSmokers' Health Protection Act, B.E. 2535, the sugarcane harvest migrant workers are considered underprivileged. They are temporarily employed and do not have employment contracts or specific rates for wages or compensation. They have a high risk of exposure to secondhand smoke but are neglected for health protection ${ }^{12}$. For this reason, this study was conducted to ascertain exposure to secondhand smoke by the informal sugarcane harvest migrant workers at the worker camp and to implement the social measures through a pre- and post-implementation assessment for the health protection of the informal sugarcane harvest migrant workers from SHS exposure.

\section{METHODS}

This study applied a mixed-method research approach and was divided into three phases (Figure 1). The data were collected from February to December of 2019.

\section{Phase 1: The situation of secondhand smoke exposure of the sugarcane harvest migrant workers at the worker camp}

\section{Quantitative method}

The study area was selected by the purposive method from the provinces with the highest number of sugarcane harvest migrant workers in the lower northern region. Sukhothai was chosen because it was the primary source of sugarcane harvesting in Thailand. The number of informal sugarcane harvest

Figure 1. Study method

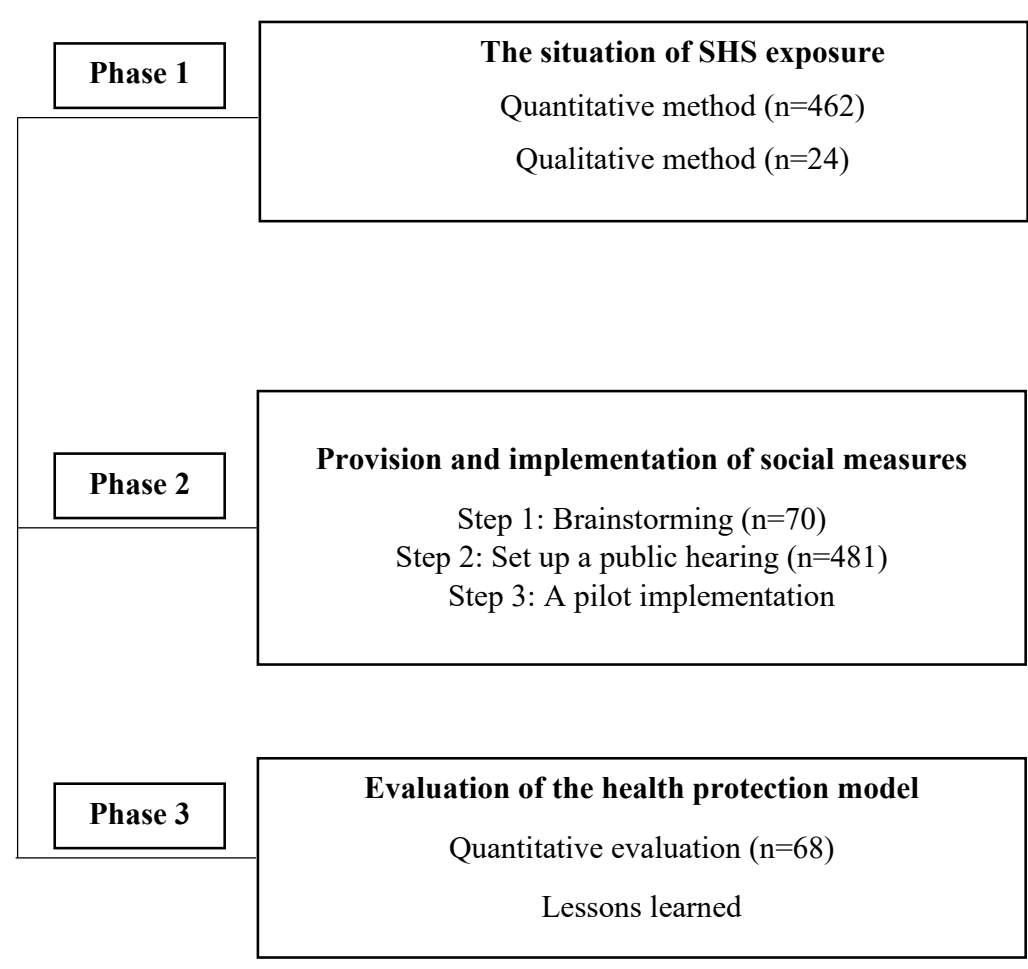


workers was higher than for other provinces in the lower northern region. By using the Cochran formula, 462 migrant workers had been randomly selected ${ }^{13}$. A questionnaire was used as a tool divided into general information involving gender, age, marital status, education level, income, duration staying in the worker camp, overtime work, and the extent of SHS exposure. Collected data were analyzed using SPSS version 20 for Windows (IBM Corp., Armonk, NY). Descriptive statistics were used to describe basic sociodemographic features, whereas differences between categorical variables were assessed for significance using the chi-squared test or Fisher's exact test, as appropriate. Binary logistic regression models were used to investigate the association between independent and dependent variables.

\section{Qualitative method}

A total of 24 sample participants comprised five smokers, three employers, four wives of smoker husbands, three heads of the workers, two cigarette shop keepers, two local government officers, two public health officers, and three non-smoking workers. Group discussion on the smoking behavior and factors leading to SHS exposure was employed. The focus group discussion consisted of questions about the general context of sugar cane harvest workers, worker camp lifestyle, the environment in camp, number of workers, the background of worker, smoking behavior of workers, the reason for smoking, mode of a new smoker, the context of SHS, and factors leading to secondhand smoke exposure. Data were collected from two discussion groups with a total of 12 members in each group. The discussion duration was 90 minutes. The data were analyzed with transcription and qualitative content analysis to categorize the items based on the research objectives ${ }^{14}$.

\section{Phase 2: Provision and implementation of social measures for health protection of the migrant workers and families from SHS exposure}

Process of social measures provision and implementation comprised the three following steps.

\section{Step 1}

A total of 70 representatives included sugarcane harvest migrant workers and families, employees, worker leaders, shop keepers, local government officials, public health officers, and the researchers were selected purposively for the brainstorming session. The result of Phase 1 was used for the topic of the brainstorming session and the draft of the social measures was determined in line with the consensus among the stakeholders.

\section{Step 2}

We set up a public hearing with 462 workers from 10 worker camps, 10 employers, six shop owners, and three public health officers. The public hearing process referred to people's opinion towards SHS problems and their solution through general public discussion, moderated by researchers and other government agencies. A public hearing gives the people's opinion, and their feedback consisted of the social measures for the health protection of the informal sugarcane harvest migrant workers from SHS exposure. Lastly, we summarized the public's comments and modified social standards and announced the final social measures.

\section{Step 3}

A pilot implementation of the social measures was conducted at four worker camps selected by the volunteer sampling method. The measures were: give a warning, not giving rewards by cigarettes, designate a smoking area, not smoking in the toilet, not convincing others to smoke, not asking the children to buy cigarettes, not dropping the cigarette butts where children may see, reducing the smoking frequency, a reminder from the family members, recommendations by ex-smokers, not displaying cigarettes and giving credit to buy cigarettes in the grocery stops, monitor the imitation of children, set up a positive environment for health, women empowerment, minimize free time to be distracted by smoking, not keeping cigarettes in a visible place at the neighboring camp and not smoking near the main hall where women and children are watching television (Table 1).

\section{Phase 3: Evaluation of the health protection model for the migrant workers and families from secondhand exposure \\ Quantitative evaluation}

The survey form about the exposure location of 


\section{Table 1. Social measures to prevent secondhand smoke exposure in migrant worker camps}

\section{Social measures}

1. Give a warning

2. No rewards by cigarettes

3. Designate a smoking area

4. Do not smoke in the bedroom and toilet

5. Do not convince others to smoke

6. Do not ask the children to buy cigarettes

7. Do not drop cigarette butts where children can see

8. Reduce the smoking frequency

9. A reminder from the family members

10. Ex-smokers give recommendations to others

11. The grocery shops stop displaying cigarettes and giving credit to buy them

12. Monitor the imitation of children

13. Set a positive environment for health

14. Women are empowered to go against the smoking husband in the camp and the sugarcane field when the women, children, and non-smokers are present

15. Minimize free time to be distracted by smoking

16. Do not put cigarettes in a visible place at the adjacent camp

17. Do not smoke near the main hall where women and children are watching television

18. Reduce the frequency of drinking in the camp to minimize smoking while drinking

\section{Methods}

Assign the employer and head of workers to give a warning.

Set the rule to encourage the workers to respect each other. Give cooperation to accept the warning and surveillance.

Set the rule to prohibit the employer from rewarding the workers with cigarettes.

The employer, head of workers, and smokers designate the smoking area in the camp and announce it to the workers.

The rule of the smoking ban in the bedroom and toilet.

Smokers should not convince non-smokers to try smoking.

The children should not be asked to buy cigarettes.

Smokers should not drop cigarette butts in the camp area to prevent smoking imitation by the children.

Convince smokers to minimize smoking.

A reminder and warning within the family.

Assign the ex-smokers to give advice.

Ask for cooperation from the cigarette shop not to display the cigarettes or offer credit.

The parents monitor imitation behavior in children.

Aim for a smoking-free camp.

Display no-smoking signs around the camp.

Arrange smoking areas outside the camp.

Support females in the camp to resist and prohibit the husbands from smoking in the camp and sugarcane field when the women are present.

Arrange activities during free time to distract from smoking, such as fishingnet weaving, wickerwork.

Do not place cigarettes in a visible place where people can easily take them at the adjacent camp, walkway, toilet, and the main hall.

The main hall in the camp center is where the workers gather to chat and watch television. Do not smoke near the hall where women and children are watching television.

Reduce the frequency of drinking and smoking in the camp. secondhand smoke was used. Data of the first part were collected from the four trial camps. The trial results were evaluated after one month of implementation compared to the number of workers exposed to secondhand smoke.

\section{Lessons learned and participatory evaluation}

The researchers and workers gave their opinion systematically to monitor and evaluate the factors of success. Data were collected from all research participants. The researchers and workers collaborated to analyze and summarize the evaluation results.

\section{RESULTS}

\section{Quantitative method}

The results showed that $71.2 \%$ of the workers were male while $28.8 \%$ were female, and $58.7 \%$ were aged $\geq 41$ years. A total of $40.5 \%$ were married, while $62.3 \%$ graduated from primary school. A total of $66.0 \%$ stayed in the worker camp for more than two years, and $74.0 \%$ reported a cigarette shop at their worker camp (Table 2). Besides, it was found that $64.7 \%$ were exposed to secondhand smoke, whereas $35.3 \%$ were not. Table 3 shows that age, marital status, and occupation were related to secondhand smoke exposure with statistical significance $\left(X^{2}=14.69\right.$, 
Table 2. Demographic characteristics of the sample, Sukhothai, 2019 ( $\mathrm{N}=462)$

\begin{tabular}{l|ll|}
\hline Characteristics & $n$ & $\%$ \\
\hline Gender & 329 & 71.20 \\
\hline Male & 133 & 28.80 \\
\hline Female & & \\
\hline Age (years) & 191 & 41.30 \\
\hline 440 & 271 & 58.70 \\
$\geq 41$ & & \\
\hline Overtime work & 187 & 40.50 \\
\hline Yes & 275 & 59.50 \\
\hline No & & \\
\hline Education level & 288 & 62.30 \\
\hline Primary school & 174 & 37.70 \\
\hline Secondary school and higher & & \\
\hline Duration of staying at the worker camp (years) & 157 & 34.00 \\
\hline$<2$ & 305 & 66.00 \\
\hline 2 & & \\
\hline Cigarette shop in the camp & 342 & 74.00 \\
\hline Yes & 120 & 26.00 \\
\hline No & &
\end{tabular}

$\mathrm{p}<0.001),\left(\chi^{2}=17.32, \mathrm{p}<0.001\right)$, and $\left(\chi^{2}=4.75\right.$, $\mathrm{p}=0.031$ ), respectively. From Table 4 , it can be seen that workers aged $\leq 40$ years had 1.93 times higher exposure to secondhand smoke than those aged $\geq 41$ years $(\mathrm{OR}=1.93 ; 95 \% \mathrm{CI}: 1.24-3.01)$. Moreover, those who worked overtime had 1.71 times more exposure to secondhand smoke than those who did not work overtime (OR=1.71; 95\% CI: 1.10-2.66).

\section{Qualitative method}

From the general information, $59.1 \%$ of the workers joining in the group discussion were males while $40.9 \%$ were female, and $30.1 \%$ were aged $30-40$ years; the mean age was 36 years. Most completed primary school (74.3\%), followed by secondary school (17.4\%). Only $6.3 \%$ were illiterate. The majority were married $(78.8 \%)$, whereas the rest were single (18.2\%) and divorced (2.9\%), while $73.6 \%$ earned 2501-6000 Tai Baht per month (about US\$31 to $1000 \mathrm{THB}$ ). Group discussion results were as follows.

\section{General context}

Sukhothai is famous for growing sugarcane, and many

Table 3. Analysis of relationships between population attributes and exposure to secondhand smoke, Sukhothai, 2019 ( $\mathrm{N}=462)$

\begin{tabular}{|c|c|c|c|c|}
\hline \multirow[t]{2}{*}{ Factors } & \multirow{2}{*}{$\begin{array}{l}\text { Total } \\
n(\%)\end{array}$} & \multicolumn{2}{|c|}{ Exposure to secondhand smoke } & \multirow[t]{2}{*}{$p$} \\
\hline & & $\begin{array}{c}\text { Yes } \\
n(\%)\end{array}$ & $\begin{array}{c}\text { No } \\
n(\%)\end{array}$ & \\
\hline \multicolumn{5}{|l|}{ Gender } \\
\hline Male & $133(28.8)$ & $83(62.4)$ & $50(37.6)$ & 0.520 \\
\hline Female & $329(71.2)$ & $216(65.7)$ & $113(34.3)$ & \\
\hline \multicolumn{5}{|l|}{ Age (years) } \\
\hline$\leq 40$ & $191(41.3)$ & $143(74.9)$ & $48(25.1)$ & $<0.001$ \\
\hline$\geq 41$ & $271(58.7)$ & $156(57.6)$ & $115(42.4)$ & \\
\hline \multicolumn{5}{|l|}{ Overtime work } \\
\hline Yes & $187(40.5)$ & $142(75.9)$ & $45(24.1)$ & $<0.001$ \\
\hline No & $275(59.5)$ & $157(57.1)$ & $118(42.9)$ & \\
\hline \multicolumn{5}{|l|}{ Education level } \\
\hline Primary school & $174(37.7)$ & $109(62.6)$ & $65(37.4)$ & 0.483 \\
\hline Secondary school and higher & $288(62.3)$ & $190(66.0)$ & $98(34.0)$ & \\
\hline \multicolumn{5}{|c|}{ Duration staying at the worker camp (years) } \\
\hline$<2$ & $157(34.0)$ & $91(58.0)$ & $66(42.0)$ & 0.031 \\
\hline$\geq 2$ & $305(66.0)$ & $208(68.2)$ & 97 (31.8) & \\
\hline \multicolumn{5}{|l|}{ Cigarette shop in the camp } \\
\hline Yes & $342(74.0)$ & $222(64.9)$ & $120(35.1)$ & 0.912 \\
\hline No & $120(26.0)$ & 77 (64.2) & $43(35.8)$ & \\
\hline
\end{tabular}


Table 4. Logistic regression analysis between population attributes and exposure to secondhand smoke, Sukhothai, 2019 ( $\mathrm{N}=462)$

\begin{tabular}{|c|c|c|c|c|c|}
\hline \multirow[t]{2}{*}{ Factors } & \multirow{2}{*}{$\begin{array}{l}\text { Total } \\
n(\%)\end{array}$} & \multicolumn{2}{|c|}{ Exposure to secondhand smoke } & \multirow[t]{2}{*}{ OR $(95 \%$ CI $)$} & \multirow[t]{2}{*}{$p$} \\
\hline & & $\begin{array}{c}\text { Yes } \\
n(\%)\end{array}$ & $\begin{array}{c}\text { No } \\
n(\%)\end{array}$ & & \\
\hline \multicolumn{6}{|c|}{ Age (years) } \\
\hline$\leq 40$ & $191(41.3)$ & $143(74.9)$ & $48(25.1)$ & $1.932(1.24-3.01)$ & 0.004 \\
\hline$\geq 41$ & $271(58.7)$ & $156(57.6)$ & 115 (42.4) & & \\
\hline \multicolumn{6}{|c|}{ Overtime work } \\
\hline Yes & $187(40.5)$ & $142(75.9)$ & $45(24.1)$ & $1.717(1.10-2.66)$ & 0.016 \\
\hline No & $275(59.5)$ & $157(57.1)$ & $118(42.9)$ & & \\
\hline
\end{tabular}

Before adjustment using $X^{2}$, the significant factors were age, overtime work, and duration staying at the worker camp. After adjustment using logistic regression, the significant factors were age and overtime work.

sugar factories are located in the province. Seasonal informal sugarcane harvest workers are coming to the province from December to April each year. Most are from the northeastern and northern regions of Thailand. Most camps were built with galvanized iron sheets in the worker camp, whereas some were constructed with bamboo with the galvanized iron roof for accommodation. The number of workers at each camp was about 50-100. The camps were primarily set in the sugarcane fields or the employer's house area.

\section{Smoking}

The number of smokers in the camp increased every year. Some started smoking this year because their smoker friends convinced them. The group opinion illustrated that working in the provinces and staying in the camp for many months might change the nondrinkers and non-smokers to drinkers and smokers because of their friends' persuasion. Further, the possibility of smoking and drinking of the nondrinkers and non-smokers was higher when they were gathering.

\section{Factors leading to exposure to secondhand smoke} Chatting and smoking during free time

The workers had free time after work. During this time, women workers prepared the meal while male workers were chatting and smoking in front of the room. After dinner, women workers and children gathered and watched television in the hall in the camp center, whereas male workers continued smoking.

\section{Drinking alcohol led to smoking}

Drinking alcohol after work at the sugarcane harvest worker camp is very common. The workers contributed money to buy rice whiskey and gathered in circles to drink it from one plastic glass around the circle. The side dish was roasted tamarind seeds. They believed that drinking alcohol relieved the pain and aches from working and helped them to have a good sleep. Moreover, some drinkers shared their cigarettes with their friends, so new smokers were from the drinkers' group.

\section{Cheap cigarettes}

Roll-up cigarettes were popular among people with low income and agriculturists in rural areas because of the low price and availability. The workers bought them from the flea markets or the grocery shops in the camp. Some had the belief that smoking roll-up cigarettes were not harmful to health.

\section{Exposure to secondhand smoke}

The members of the discussion group had different experiences of exposure to secondhand smoke. Some were exposed from their husbands, colleagues, or the teenagers in the sugarcane fields. Morning and evening at the camp area were when they were exposed to secondhand smoke the most because the workers were living together at the camp; the exposure locations were the eating spaces, toilets, quad, bedroom while watching television, and in bed. They were also exposed to secondhand smoke while travelling from the camp to the worksite in the morning and evening and at the harvest area. 
Table 5 illustrates that before implementing the measures (by the workers), there was $45.5 \%$ SHS exposure in front of the room, followed by the main hall $(33.8 \%)$ and inside the room $(32.3 \%)$. After implementing the measures (by the same workers), only $5.8 \%$ of SHS exposure occurred in the room, whereas none smoked in the main hall and inside the room.

\section{Results of lessons learned on the social measures Employer}

The employer played a crucial role in moving the social measures forward to control and prevent new smokers and protect the non-smokers' health among the migrant workers at the worker camp. The employer selected and invited the workers, who might be in the same group as the previous year, to work and stay at the camp. For this reason, the relationship between the employer and workers is quite positive. Consequently, the request not to smoke in the camp is heeded and the workers also showed respect to the employer. Furthermore, some families received their pay in advance and returned to work to repay in the following year, so they were considerate and did not refuse what the employer was asking them to do. Besides, many employers offered help to their workers regarding essentials such as rice, consumer goods, water, and electricity to persuade them to consider coming to work with them again in the following year.

Table 5. Evaluation results of social measures effectiveness, Sukhothai, 2019

\begin{tabular}{|c|c|c|c|c|}
\hline \multirow[t]{2}{*}{$\begin{array}{l}\text { Location of secondhand } \\
\text { smoke exposure }\end{array}$} & \multicolumn{2}{|c|}{$\begin{array}{c}\text { Before measures } \\
\text { implementation } \\
(n=68)\end{array}$} & \multicolumn{2}{|c|}{$\begin{array}{c}\text { After measures } \\
\text { implementation } \\
\qquad(n=68)\end{array}$} \\
\hline & $n$ & $\%$ & $n$ & $\%$ \\
\hline 1. In the room & 22 & 32.35 & 0 & 0 \\
\hline 2. In front of the room & 31 & 45.58 & 2 & 5.8 \\
\hline 3. At the corner in the camp & 19 & 27.94 & 1 & 2.9 \\
\hline 4. In the toilet & 18 & 26.47 & 2 & 5.8 \\
\hline 5. Public bathroom & 12 & 17.64 & 2 & 5.8 \\
\hline $\begin{array}{l}\text { 6. Main hall for watching } \\
\text { television }\end{array}$ & 23 & 33.82 & 0 & 0 \\
\hline 7. Camp entrance & 21 & 30.88 & 1 & 2.9 \\
\hline 8. Cooking area & 10 & 14.70 & 0 & 0 \\
\hline $\begin{array}{l}\text { 9. At the quad in the center } \\
\text { of the camp }\end{array}$ & 13 & 19.11 & 0 & 0 \\
\hline 10. At the washing area & 8 & 11.76 & 2 & 5.8 \\
\hline
\end{tabular}

\section{Leader of the workers}

The workers' leader controlled and monitored the workers' orders and coordinated with the employer. The leader of workers was selected by voting from all the workers. Therefore, the workers had a close relationship with the leader. He might be a friend, relative, or someone from the same village who worked in the camp. Living together was the opportunity for them to talk and persuade smoking workers to limit the smoking time and not publicly smoke. The leader customarily cooked, travelled to the field, and ate together with the workers, so they had adequate time to talk and warn each other.

\section{Housewives}

Some of the housewives' prominent roles were cooking, taking care of the child, and working in the field with the husband. They would ask the husband to smoke outside the camp because they were aware of the impacts of smoke and their children's health. For this reason, the housewives were the influential people who controlled smoking in the worker camp effectively.

\section{Public health officers}

The key roles were to take care of the health of the workers in the camp and educate them about SHS exposure via various channels, such as pamphlets, posters, no-smoking stickers, individual training about health education, and group feedback to the community to inform them of the smoking and SHS exposure situation, as well as the impacts on the workers' health. As a result, the workers started to show concern about the harm of secondhand smoke. In this research, the public health officer enforced the social measures by giving examples from experience in the care of patients with smoking problems to create awareness and motivation to reduce the frequency and quit smoking.

\section{DISCUSSION}

The results showed that the different social measures include self-awareness, social norms, the arrangement of an environment facilitating the new norms, empowering women to stop the husbands who smoked in the camp and the fields, and reducing free time to distract the workers from smoking reduced SHS exposure. Moreover, the measures also included not placing cigarettes in visible places that made it 
easy to smoke in the neighboring camps, no smoking in the main hall where the women and children watched television and minimizing drinking alcohol in the camp to reduce smoking while drinking, all helped reduce SHS exposure. After one month of implementing the measures, the evaluation results illustrated that the experimental group was less exposed to secondhand smoke. The relatives and family members smoked less and were able to warn smokers. Moreover, the employer cooperated in giving warnings. Self-awareness has been found a significant attribute to the cession of smoking, this helps to reduce SHS exposure ${ }^{15}$. Besides, a recent study conducted in Bangladesh found that practicing social norms helped reduce SHS exposure among children ${ }^{16}$. The result also was in line with another study in Canada among young adults ${ }^{17}$. Our study showed woman empowerment as a significant factor in line with other studies conducted in South Asia ${ }^{16,18}$. Smoking in a visible place increases a non-smoker's chances to start smoking and increasing SHS, which was also found in a study conducted in England ${ }^{19}$. Besides alcohol drinking increases smoking as was also found by previous research ${ }^{20}$. In addition, our research also found long working hours result in working stress which is related to smoking, also in line with a study from Finland ${ }^{21}$.

The social measures to protect the health of migrant workers and families from SHS exposure were determined based on the perspectives of the relevant people and the root of the problems. The measures were developed from informal retrieval and the participation and support from the relevant sectors, including the employers, officers, and shop owners, who expressed their opinions, made decisions and took part in the operation via the public hearing until the workers' community accepted and processed the solutions by themselves. However, some aspects were unable to be processed, such as academic information for which the assistance of the government sector was required. It is evident that social measures needed support from the public health officers to operate, entrepreneurs' decision-making to control and monitor, and the grocery shops to set the market mechanism and implement the social measures.

\section{Strengths and limitations}

Social measures are a significant strength of the present research, used also in other settings to minimize the SHS exposure. Despite this strength, we used a cross-sectional study in one of the phases, which only gives a particular time picture. Besides, in the group discussions, the sample size was small, which may affect the outcome, and one month is a very short duration to evaluate the effect of social change measures. The study also neglected populations in Thailand that moved around the country for employment.

\section{CONCLUSIONS}

Our research is one of the first of this kind of study focused on the sugarcane migrant workers' exposure to secondhand smoke. The results showed that social measures help smokers to reduce secondhand smoke exposure to their close ones. For the sustainability of any social measure, a long-term evaluation is recommended to get proper outcomes.

\section{REFERENCES}

1. World Health Organization. Tobacco Control. Accessed July 17, 2020. https://www.who.int/gho/tobacco/use/ en/

2. Centers for Disease Control and Prevention. Health Effects of Secondhand Smoke. Accessed 30 March 2019, 2019. https://www.cdc.gov/tobacco/data_statistics/fact_ sheets/secondhand_smoke/health_effects/index.htm

3. World Health Organization. Global Health Observatory data repository. Accessed January 16, 2021. http://apps. who.int/gho/data/view.main.1805REG?lang=en

4. World Health Organization. Tobacco. May 27, 2020. Accessed January 16, 2021. https://www.who.int/newsroom/fact-sheets/detail/tobacco

5. European Commission. Tobacco or Health in the European Union: Past, Present and Future. European Communities; 2004. Accessed January 16, 2021. http:// ec.europa.eu/health/archive/ph_determinants/life_style/ tobacco/documents/tobacco_fr_en.pdf

6. Centers for Disease Control and Prevention. Secondhand Smoke (SHS) Facts. Accessed October 26, 2016. https:// www.cdc.gov/tobacco/data_statistics/fact_sheets// secondhand_smoke/general_facts/

7. World Health Organization. Global Adult Tobacco Survey (GATS). Fact Sheet. Thailand: 2009. 2009. Accessed January 16, 2021. https://www.who.int/tobacco/ surveillance/fact_sheet_gats_thailand_2009.pdf

8. Ham DC, Przybeck T, Strickland JR, Luke DA, Bierut LJ, Evanoff BA. Occupation and workplace policies predict smoking behaviors: analysis of national data from the current population survey. J Occup Environ Med. 2011;53(11):13371345. doi:10.1097/JOM.0b013e3182337778 
9. Olivieri M, Murgia N, Carsin AE, et al. Effects of smoking bans on passive smoking exposure at work and at home. The European Community respiratory health survey. Indoor Air. 2019;29(4):670-679. doi:10.1111/ina.12556

10. van den Brand FA, Nagelhout GE, Winkens B, Chavannes NH, van Schayck OCP, Evers SMAA. Cost-effectiveness and cost-utility analysis of a work-place smoking cessation intervention with and without financial incentives. Addiction. 2020;115(3):534-545. doi:10.1111/add.14861

11. Food and Agriculture Organization of the United Nations. Thailand. Accessed December 7, 2020. http://www.fao. org/3/X0513E/x0513e24.htm

12. Manoton A, Juwa S, Wongwat R. Tobacco consumption and secondhand smoking in temporary migrant workers in the context of Thailand's tobacco control policy: migrant workers temporarily cut sugar cane Sukhothai Province. 2010.

13. Cochran WG. Sampling Techniques. 3 ed. John Wiley \& Sons; 1977. Accessed December 7, 2020. https:// glad.geog.umd.edu/Potapov/_Library/Cochran_1977_ Sampling_Techniques_Third_Edition.pdf

14. Erlingsson C, Brysiewicz P. A hands-on guide to doing content analysis. Afr J Emerg Med. 2017;7(3):93-99. doi:10.1016/j.afjem.2017.08.001

15. Liebling BA, Seiler M, Shaver P. Self-awareness and cigarette-smoking behavior. Journal of Experimental Social Psychology. J Exp Soc Psychol. 1974;10(4):325332. doi:10.1016/0022-1031(74)90029-8

16. Robin RC, Noosorn N, Alif SM. Secondhand Smoking Among Children in Rural Households: A Community Based Cross-Sectional Study in Bangladesh. Osong Public Health Res Perspect. 2020;11(4):201-208. doi:10.24171/j.phrp.2020.11.4.09

17. Glenn NM, Lapalme J, McCready G, Frohlich KL. Young adults' experiences of neighbourhood smoking-related norms and practices: A qualitative study exploring place-based social inequalities in smoking. Soc Sci Med. 2017;189:17-24. doi:10.1016/j.socscimed.2017.07.021

18. Jackson C, Huque R, Satyanarayana V, et al. "He Doesn't Listen to My Words at All, So I Don't Tell Him Anything"-A Qualitative Investigation on Exposure to Second Hand Smoke among Pregnant Women, Their Husbands and Family Members from Rural Bangladesh and Urban India. Int J Environ Res Public Health. 2016;13(11):1098. doi:10.3390/ijerph13111098

19. McKeganey N, Barnard M, Russell C. Visible Vaping: E-Cigarettes and the Further De-Normalization of Smoking. International Archives of Addiction Research and Medicine. 2016;2(2). doi:10.23937/2474-3631/1510023

20. Bien TH, Burge R. Smoking and drinking: a review of the literature. Int J Addict. 1990;25(12):1429-1454. doi:10.3109/10826089009056229

21. Kouvonen A, Kivimäki M, Virtanen M, Pentti J, Vahtera J. Work stress, smoking status, and smoking intensity: an observational study of 46,190 employees.
J Epidemiol Community Health. 2005;59(1):63-69. doi:10.1136/jech.2004.019752

\section{ACKNOWLEDGEMENTS}

The authors would like to acknowledge the Tobacco Control Research of Thailand foundation for the funding of the research.

\section{CONFLICTS OF INTEREST}

The authors have each completed and submitted an ICMJE form for disclosure of potential conflicts of interest. The authors declare that they have no competing interests, financial or otherwise, related to the current work. All authors report support from the Tobacco Control Research of Thailand foundation.

\section{FUNDING}

This study was funded by Tobacco Control Research of Thailand foundation.

\section{ETHICAL APPROVAL AND INFORMED CONSENT}

Ethical approval was given by the Naresuan University Research Ethics Committee (No. 5202030002, 20 November 2018). Participation in the discussions was taken as informed consent.

\section{DATA AVAILABILITY}

The data supporting this research are available from the authors on reasonable request.

\section{PROVENANCE AND PEER REVIEW}

Not commissioned; externally peer reviewed. 